\title{
Biblioteca escolar como espaço de reinvenções curriculares
}

\author{
School library as a space for reinvention of curriculum
}

\begin{abstract}
Eduardo Valadares da Silva
Mestrando do Programa de Pós Graduação em Educação da Universidade Federal do Espírito Santo. Bibliotecário da Rede de Bibliotecas Escolares da Secretaria de Educação da Prefeitura Municipal de Vitória, Contador de Histórias e Delegado do Conselho Regional de Biblioteconomia $6^{\mathrm{a}}$ Região MG/ES.

E-mail: edu_valadares@yahoo.com.br

Fabiano de Oliveira Moraes

Doutorando em Educação, pela Universidade Federal do Espírito Santo - UFES. Professor de Pós-graduação do Instituto Fênix. E-mail: contato@fabianomoraes.com.br
\end{abstract}

\section{Resumo}

O presente trabalho apresenta reflexões acerca da biblioteca escolar concebida sob uma perspectiva de espaço de reinvenções curriculares utilizando Michel de Certeau como o principal referencial teórico norteador das reflexões aqui apresentadas. Trata-se de um estudo de caso que lança mão de estudo bibliográfico para estabelecer uma aproximação com a Rede de Bibliotecas Escolares da Prefeitura Municipal de Vitória no Espírito Santo, adotada aqui como objeto de análise, por se tratar de uma Rede que conta com um bibliotecário atuando em cada uma de suas unidades de Ensino Fundamental desde o ano de 2006. Objetiva demonstrar que ainda assim existem alguns desafios que estão ligados principalmente ao reconhecimento da biblioteca como um espaçotempo de constituição do currículo escolar e ao processo de construção de uma identidade do bibliotecário como um sujeito educador, ainda que biblioteca e bibliotecários não sejam oficialmente considerados nas Diretrizes Curriculares que norteiam o Ensino Fundamental neste Município. Nesse contexto apresenta uma análise de movimentos cotidianos buscando fugir das relações de poder por vezes já preconcebidas à biblioteca escolar criando suas próprias maneiras de constituição do currículo nesse espaço levando em consideração a singularidade dos sujeitos e a compreensão da prática a partir do envolvimento cotidiano.

Palavras chave: Biblioteca educadora. Biblioteca escolar. Cotidiano. Currículo.

\begin{abstract}
Using Michel de Certeau as the main theoretical framework guiding, this study presents reflections about the school library conceived from the perspective of space for reinventions of curriculum. It is about a case study that makes use of bibliographical study to establish an approach with the School Library Network of the City of Vitória in Espírito Santo, adopted as object of analysis, for it is a Network that has one librarian working in each of its units Elementary School since 2006. Aims to demonstrate that still there are some challenges that are linked mainly to the recognition of the library as a space-time of constituting the school curriculum and the process of building an identity as a subject of the librarian educationalist, although library and librarians are not officially considered in the Curricular Guidelines that orient the elementary school in this city. In this context presents an analysis of everyday life movements that happen, seeking escape from power relations often have preconceived school library which creates its own ways of setting up the curriculum in that space taking into account the singularity of the subject and comprehension of practice through the involvement in everyday life.
\end{abstract}

Keywords: Educating library. School library. Everyday life. Curriculum. 


\section{Introdução}

Pretende-se refletir aqui acerca de algumas possibilidades de compreensão de aproximações e afastamentos entre escola - biblioteca escolar - escola considerando como referencial a perspectiva cotidianista de Michel de Certeau. O interesse por essa análise surge do entendimento de que todo o espaço escolar caracteriza-se fundamentalmente como espaçotempo ${ }^{l}$ de ensinoaprendizagem, como se pode perceber não apenas nos discursos estabelecidos acerca de tal instituição ou nas concepções teóricas, mas principalmente em suas práticas cotidianas, incluindo nesse contexto os espaçostempos da biblioteca escolar como também constituinte e lócus daqueles sujeitos praticantes que realizam o currículo na escola.

Essas reflexões acerca das aproximações e afastamentos se darão relacionando os discursos teóricos cotidianistas à realidade da Rede de Bibliotecas Escolares da Prefeitura de Vitória no estado do Espírito Santo. A opção por tomar como caso essa Rede se dá pelo fato de a cidade de Vitória se caracterizar como uma das poucas capitais, se não a única capital do país, a contar com uma Rede de Bibliotecas Escolares com profissionais bibliotecários atuando em cada uma das 52, das 53 unidades de Ensino Fundamental existentes no Município, e que ainda assim, nos dias de hoje, estabelece ou cria resistências à realização de um trabalho que integre a biblioteca ao coletivo da escola, restringindo assim as possibilidades de saberesfazeres que poderiam se constituir em redes na, e com a biblioteca escolar, e nas diversas possibilidades a partir desta.

Quando da oportunidade de um dos autores deste artigo de coordenar o trabalho dessa Rede nos anos de 2010, 2011 e 2012 compreendeu-se um pouco melhor como se constituem as múltiplas relações que acontecem nesses espaçostempos, mais especificamente em torno da biblioteca escolar, em contraposição a um estigma ainda presente em grande parte da sociedade, inclusive na concepção de alguns educadores, a partir do qual se compreende a biblioteca como um espaço de silêncio, guarda e empréstimo de livros, desconectado do cotidiano da escola e alheio às práticas curriculares (levando-se em conta o modo como tradicionalmente se concebe a prática curricular: como execução do que foi prescrito). Em

\footnotetext{
${ }^{1}$ Neste artigo são utilizados alguns termos hifenados (em alusão à estética da escrita de Nilda Alves que tem por intuito, ao unir palavras, inventar outras tantas) para destacar a intencionalidade de provocar a reflexão acerca do fato de que a maioria dos processos, principalmente no fazer educativo, não acontece seguindo uma ordem hierárquica ou de etapas pré-estabelecidas, mas sim em uma dinâmica de redes que fogem ao nosso controle, sem um começo ou fim claramente demarcados.
} 
contrapartida, é possível encontrar na prática trabalhos muito potentes realizados conjuntamente por bibliotecários e demais constituintes das equipes escolares junto aos alunos e grande parte da comunidade escolar, o que mostra a diversidade de possibilidades de mediação pedagógica tendo como ponto de partida os espaçostempos da biblioteca escolar colocando por terra discursos que privilegiam as impossibilidades, as fixações de modelos pré-concebidos e os distanciamentos das realidades tecidas pelos sujeitos da escola. Compreende-se a biblioteca escolar, assim como toda a diversidade de espaçostempos da escola, como elemento imprescindível para a constituição da subjetividade do estudante, não somente pela organização e disponibilização de acervos, mas também pela viabilização dos saberesfazeres que nele se fazem presentes e dele emergem, subsidiados pela sua existência, tomando por base a realidade da escola, seu projeto político-pedagógico e a cultura que fundamenta os modos de vida dos sujeitos constituintes da, e constituídos pela comunidade escolar.

A entrada de bibliotecários no Sistema de Ensino de Vitória ocorreu no ano de 2005 por meio do concurso público de edital $n^{\circ} 001 / 2005$ que foi fruto de um trabalho experimental realizado entre no período de 1997 e 2005 nas escolas do Município que consistia em envolver bibliotecários, professores de diversas áreas do conhecimento e estagiários que se mobilizavam em programa de reestruturação dos espaços escolares, sendo que a biblioteca acabou por se constituir como a ação desse programa que obteve maior destaque. Diante disso infere-se que o bibliotecário escolar é um profissional ainda recente no sistema de ensino de Vitória, e por isso, em muitos momentos, é visto com resistência pelos demais sujeitos da escola (ousa-se estender esse quadro para a maior parte dos sistemas ou redes de ensino público do país). Compreendeu-se essa situação não de um lugar exclusivamente teórico ou sobre um pedestal gestor, mas vivenciada no dia a dia na atuação do bibliotecário coautor deste artigo em duas unidades de Ensino Fundamental dessa Rede por cerca de dois anos e meio, o que leva a crer que ainda há muito que se aprimorar no trabalho da Rede de Bibliotecas Escolares de Vitória, principalmente no que tange às relações de mediação pedagógica e à atuação em rede entre o profissional bibliotecário e os demais sujeitos da escola, bem como na institucionalização oficial das Redes de Bibliotecas Escolares. 


\section{Bibliotecário escolar como sujeito educador ou meramente técnico?}

Não se pretende defender aqui uma perspectiva de atuação do bibliotecário escolar que desconsidere a importância e a necessidade de um tratamento da informação com qualidade, mas sim que essa atividade seja concebida como uma função meio da biblioteca escolar, visto que na maioria das vezes são raros os casos de disponibilidade de um bibliotecário com dedicação exclusiva ao tratamento da informação. O que se tem percebido é a disponibilidade de um mesmo sujeito que distribui sua organização de tempo em todas as funções demandadas pela dinâmica exigida por uma biblioteca escolar.

Campello (2010, p. 190) defende a perspectiva de atuação de Bibliotecas e Bibliotecários(as) Educadores(as) na qual a integração e cooperação entre bibliotecários, professores, pedagogos e toda equipe da escola se torna imprescindível e o bibliotecário passa a se reconhecer e ser reconhecido como catalizador/protagonista dessa colaboração, participando de ações de relacionamento, não apenas com os professores individualmente, mas buscando em meio aos sujeitos praticantes uma cultura de colaboração na escola. Assumindo esse papel, pretende-se que o bibliotecário seja um importante orientador, no sentido de elucidar questões sobre a natureza do ensinoaprendizagem, em um ambiente permeado por abundância informacional, propiciando a efetivação, também na biblioteca, do atravessamento das teoriaspráticas deflagradas no ambiente escolar.

Em consulta às Diretrizes Curriculares para o Ensino Fundamental de Vitória (VITÓRIA, 2004), em momento algum se identificam pistas que remetam a vislumbrar explicitamente a biblioteca, tampouco o bibliotecário, fazendo parte do contexto escolar.

Tomando-se como exemplo essa realidade encontrada nos registros das Diretrizes Curriculares de Vitória, percebe-se como

\footnotetext{
[...] o currículo se tornou formalizado, abstrato e distante das conversações como um "acontecimento" na mesma proporção em que o processo de educação tem sido institucionalizado e burocratizado. [...] A distância entre conversação e prática educacional tem sido intensificada pela burocratização do currículo, em que o saber escolar aparece como forma inserida num diagrama de forças de poder fazer e dizer (CARVALHO, 2009, p. 183).
}

E ainda que tais Diretrizes estejam formalmente em vigor, observam-se suas mudanças práticas, pois “[...] à medida que nos envolvemos com elas, refletimos sobre elas, consideramos sua complexidade tecida em rede de conversações e agimos em direção à sua 
realização, buscando nos afetos e afecções a potência inventiva de um currículo não burocratizado e normalizado" (CARVALHO, 2009, p. 196).

No entanto é perceptível o quanto, ainda assim, os envolvidos nos processos educacionais participam da constituição do currículo por meio dos seus saberesfazeres e de suas teoriaspráticas que não necessariamente correspondem às Diretrizes, e que de alguma forma inserem a biblioteca no processo de ensinoaprendizagem da escola por meio de movimentos contra-hegemônicos que são produzidos em contraposição ao que é colocado pelo currículo oficial, ignorando em certa medida os processos curriculares verticalizados.

Assim, são de extrema relevância reflexões acerca das formas como a biblioteca escolar se insere na realização do currículo das escolas de Ensino Fundamental que tomem por base uma concepção de currículo que vá para além de documentos escritos ou prescritos, que mesmo considerando tais documentos, vislumbrem a potência dos currículos praticados pela pluralidade de sujeitos da escola.

Analisar essas práticas significa

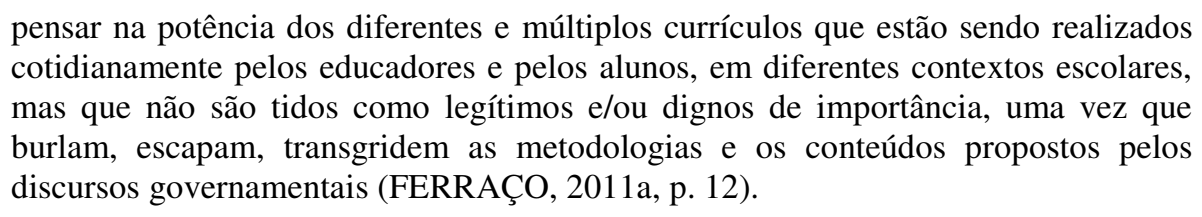

Para tanto, faz-se necessário que se reconheça “[...] aqueles que vivem, convivem, inventam, usam, praticam, habitam, ocupam nesses cotidianos" (FERRAÇO, 2003, p. 168), bem como os sujeitos cotidianos da educação em seus discursos como autores que, fazendo uso de outras possibilidades estéticas que não apenas a escrita, exercem, praticam e reinventam a cada instante o currículo (FERRAÇO, 2003).

Isso se dá pelo fato das práticas de tais sujeitos se constituírem em narrativas que subvertem as estratégias de poder, permeando e efetivando o currículo em sua amplitude, isto se dá em virtude de se tratar, neste âmbito, de

[...] currículos que não se deixam aprisionar todo o tempo por identidades culturais ou políticas, originais ou fixas. Currículos que ameaçam, em alguns momentos, o discurso oficial de uma proposta única e coerente para todo o sistema. Currículos que, em suas práticas, abrem brechas que desafiam o instituído (FERRAÇO, 2007a, p. 90). 


\section{Biblioteca escolar como espaço de reinvenções}

Com base no pensamento certauniano, adotou-se aqui uma concepção de sujeitos praticantes (professores, pais, estudantes, vigilantes, merendeiras, bibliotecário, comunidade, etc) e do modo como estes transformam e reinventam, por meio dos usos e das práticas na/da/com a escola, as teorias colocadas pela ciência moderna, num período ainda de transição, pois ali se configuram como autores da escola, utilizando-se de táticas e artimanhas para terem condições de se constituírem em um território ditado por concepções dicotômicas que, com frequência, reduzem tais relações complexas e em rede em conceitos opostos tais como a opressão e submissão daqueles considerados mais fortes sobre os fracos, do Ocidente sobre o Oriente, do rico sobre o pobre.

Para Certeau (2008) o homem ordinário inventa o cotidiano por meio de táticas de resistência, alterando os objetos e os códigos, reapropriando os espaços e os usos ao seu modo, procurando do seu melhor jeito abrir novos caminhos próprios. Segundo Certeau (2008, p. 101), “[...] a astúcia é possível ao fraco, e muitas vezes apenas ela, como 'último recurso': 'Quanto mais fracas as forças submetidas à direção estratégica, tanto mais esta estará sujeita à astúcia'. Traduzindo: tanto mais se torna tática”. Para Certeau (2008, p. 101), a tática

é a ação calculada que é determinada pela ausência de um próprio. [...] ela opera golpe por golpe, lance por lance. Aproveita 'ocasiões' e delas depende, sem base para estocar benefícios, aumentar propriedade e prever saídas. [...] este não-lugar lhe permite sem dúvidas mobilidade, mas numa mobilidade aos azares do tempo, para captar no voo as possibilidades oferecidas por um instante.

Ou seja, essas táticas acontecem como um movimento de tentativa de fuga às operações de poder que buscam o controle dos espaços sociais. São ações correlatas aos processos enunciativos, e que devem ser encaradas como possibilidades dos professores ultrapassarem suas trajetórias ou um lugar próprio de uma autoria individualizada rumo a um projeto de criação coletiva contextualizada (CARVALHO, 2009, 2012).

E é por motivo dessas mobilidades, instabilidades e desprendimentos que

\footnotetext{
Os sujeitos cotidianos, a cada dia, inventam-se e, ao se inventarem, inventam a escola. Por isso não há repetição, não há mesmice. A rotina é algo que se realiza a cada dia de forma diferente e que se expressa nas tentativas de enfrentamentos das questões que se colocam nas escolas. A cada dia, há outras questões e outros enfrentamentos, com a marca da humildade dos praticantes, ao assumirem que não podem e não conseguem controlar tudo e todos ao mesmo tempo, cientes de que a lógica determinista e causal não lhes possibilita uma ação que rompa com as estruturas que aprisionam a vida na escola (FERRAÇO, 2007b, p. 20).
} 
Ainda que se saiba da existência de um "padrão" de comportamento e atividades esperados para uma biblioteca, ora por parte dos educadores, ora por parte dos estudantes, todos esses sujeitospraticantes desenvolvem suas próprias táticas para subverterem essas normas e a partir da biblioteca fazerem os usos ou modos de fazer que mais lhe agradem, sem que para isso rejeitem diretamente essas "normas". Conforme Oliveira (2005, p. 104),

Na realidade cotidiana, há sempre locais e situações onde táticas e alternativas são postas em prática de modo a minimizar os problemas vinculados às normas conservadoras, evitar os efeitos de e de outras políticas, o que nos permite, por um lado, afirmar a permanência de um certo espaço de exercício de autonomia dos sujeitos sociais e, por outro, mais importante, constatar que os modelos (sempre generalizantes) avaliativos do real, se nos permitem compreender globalmente os fenômenos [...]

Indo ao encontro de Carvalho (2009, p. 164),

uma escola geométrica e arquitetonicamente definida é transformada em espaços pelos professores, alunos e por outros agentes por meio de suas práticas discursivas que transformam incessantemente lugares em espaços ou espaços em lugares. Os espaços exibem operações que permitem percursos, passagens, intercâmbios, trocas, compartilhamentos e não apenas determinação da lei de um "lugar próprio", pois a lei de um "lugar próprio" se expressa pela autoria definida e, portanto, pela criação, mesmo que personalizada, individualizada.

Há que se priorizar a consideração às pluralidades e necessidade de um trabalho pedagógico pensado a partir das singularidades de pessoas ou de grupos, sem que para isso sejam reduzidos um ao outro, pois a instauração de espaçostempos se faz tendo como base o "lugar próprio", que necessita se abrir para a produção de redes relacionais (CARVALHO, 2009).

Ainda para Carvalho (2009, p. 171),

\begin{abstract}
A construção de redes comuns, baseadas no intercâmbio de conhecimentos e informações, na invenção de linguagens a potência dos afetos são táticas que perfuram os sistemas de domínio. Portanto, ao estratégico se deve acrescentar o tático, visto que a lógica da tática é a de esvaziar, deslocar, utilizar e, de qualquer maneira, desestabilizar o poder imperial.
\end{abstract}

No cotidiano da escola, incluindo também o espaçotempo da biblioteca, percebe-se de que modo os seus sujeitospraticantes buscam diferentes maneiras de articular diversas táticas, como por exemplo, por meio da oralidade e das diversas linguagens que vêm imbricadas de significados, gerando com um isso um fissuramento entre a língua e o modo como a mesma é utilizada cotidianamente.

Assim como Carvalho (2009, p. 188), considera-se que o "[...] currículo escolar, como redes de conversações e ações complexas, busca os possíveis de sua constituição fundado na 
dimensão da conversação para a recriação de saberes, fazeres e afetos da/na escola como uma comunidade". Diante do exposto, há convicção de que biblioteca escolar e currículo escolar são indissociáveis e que ambos se constituem um ao outro em meio a uma rede de espaçostempos e de sujeitos praticantes.

Buscar discutir sobre as práticas da biblioteca escolar analisando seu cotidiano pressupõe integralmente o envolvimento, a participação, a problematização, o conflito, a dúvida, a dificuldade de encontrar respostas (se é que por meio deste artigo procuram-se respostas e se é que existem respostas, por isso problematiza-se, nos termos foucaultianos). Assim é necessário explorar os usos dos acervos, dos equipamentos, das tecnologias e dos objetos, ou seja, todos os sujeitos que deixam suas marcas no dia-a-dia, que compõem o cotidiano da escola, na diversidade de relações que ali e a partir dali são estabelecidas, ou seja: estudantes, professores, bibliotecários, estagiários, técnicos de todos os níveis e também aqueles sujeitos que compõem as redes estabelecidas para além do território da escola, que se configuram como sujeitos potenciais que direta ou indiretamente também estão envolvidos na tessitura das redes cotidianas.

Reflexões a partir desse tipo de abordagem estabelecem

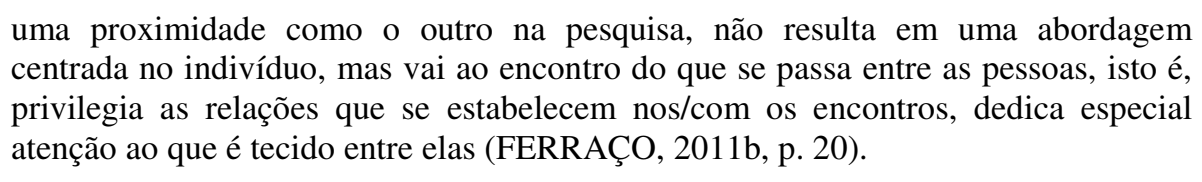

Nessa tentativa, defendem-se aqui metodologias de estudos do/no/com o cotidiano, ou seja, nas conversações, nas reuniões, nas atividades porventura ainda elencadas como curriculares ou extracurriculares, nas burlas, nas relações, enfim, na convivência com os movimentos que provocam marcas e os que passam despercebidos no cotidiano da escola.

Narrar histórias [e ouvir histórias], é pois uma forte experiência humana (...). Nesses
espaçostempos cotidianos, a cultura narrativa tem grande importância por garantir
formas, de certa maneira, duradouras aos conhecimentos, por poderem ser repetidas
e recriadas, isto porque, embora, naturalmente, tenham um conteúdo que não garante
a sua fixação, permitem uma ressignificação, uma história diferente das que
conhecemos em relação aos conhecimentos científicos ou políticos oficiais que são,
sobretudo escritos (ALVES; GARCIA, 2002, p. $274-277^{2}$ apud FERRAÇO, 2011b,
p. 44).

Com essa abordagem, as pesquisas e análises poderão trazer uma riqueza de discursos que "ampliem o presente para incluir nele muito mais experiência" (SANTOS, 2007, p. 26)

\footnotetext{
${ }^{2}$ ALVES, Nilda; GARCIA, Regina Leite. A necessidade de orientação coletiva nos estudos sobre o cotidiano: duas experiências; In: BIANCHETTI, Lucídio; MACHADO, Ana Maria Netto (Org.). A bússula do escrever: desafios e estratégias na orientação de teses e dissertações. São Paulo: Cortez, 2002. p. 255-296.
} 
por meio de uma visão sensível daqueles diversos fatores que formam o que se chama currículo vivido pelos sujeitospraticantes da escola.

\section{Considerações finais}

É perceptível ao longo deste trabalho que é necessário compreender a biblioteca escolar como um espaço imprescindível de aprendizagem não só na escola, mas em suas diversas extensões. O caso da cidade de Vitória, que conta com profissionais bibliotecários habilitados atuando em todas as unidades de Ensino Fundamental, infelizmente ainda é uma exceção na realidade do Brasil, contudo ainda há que se perseguir nesta Rede um trabalho mais articulado ao cotidiano escolar e que rompa com estigmas arraigados à biblioteca, principalmente no caso da escolar, que ainda prezam pelo silêncio, pela organização impecável com principal objetivo, pelo balizamento em um conjunto de regras inflexíveis tornando esses espaços por muitas vezes intangível para a maioria do público. A mudança desse paradigma ainda encontra-se em processo de construção, visto que a entrada do bibliotecário no espaço escolar sob uma nova perspectiva de atuação ainda é recente, se comparado, por exemplo, à do professor, gerando com isso incompreensão e resistência dos demais atores da escola a uma atuação articulada em torno do currículo escolar tomando como uma das possibilidades da biblioteca escolar. Percebe-se claramente isso quando os documentos que são construídos para serem as diretrizes norteadoras da escola ainda não contemplam, ou tampouco citam, a biblioteca escolar e o bibliotecário como também responsáveis pela constituição e prática do currículo escolar. Ainda assim, pesquisas científicas e a prática cotidiana têm buscado romper com essa perspectiva quebrando padrões e normas preestabelecidas e buscando novas formas de atender as singularidades dos sujeitos praticantes da escola levando em consideração a compreensão do cotidiano escolar e o permanente envolvimento e interferência nele. 


\section{Referências}

CAMPELLO, Bernadete Santos. Perspectivas de letramento informacional no Brasil: práticas educativas de bibliotecários em escolas do ensino básico. Encontros Bibli, v. 15, p. 184-208, 2010 .

CARVALHO, Janete Magalhães. O cotidiano escolar como comunidade de afetos. Rio de Janeiro: DP et Alli; Brasília: CNPQ, 2009.

Potência do olhar e da voz não dogmáticos dos professores na produção dos territórios curriculares. In: DP et Alli, 2012. p. 15-48. . (Org.). Infância em territórios curriculares. Petrópolis:

CERTEAU, Michel de. A invenção do cotidiano: 1. artes de fazer. 14. ed. Petrópolis: Vozes, 2008 .

FERRAÇO, Carlos Eduardo. Eu, caçador de mim. In: GARCIA, Regina Leite (Org.). Método: pesquisa com o cotidiano. Rio de Janeiro: DP\&A, 2003. p. 157-175.

As práticas teóricas de professoras e professores das escolas públicas ou sobre imagens em pesquisas com o cotidiano escolar. Currículo sem fronteiras, v. 7. n. 2. p. 7892, jul./dez. 2007a.

Apresentação: currículo e imagem e narrativa e rede e experiência e diferença e/ou sobre conversas, encontros e devires. In: (Org.). Currículo e educação básica: por entre redes de conhecimentos, imagens, narrativas, experiências e devires. Rio de Janeiro: Rovelle, 2011a. p. 11-16.

Currículos em realização com os cotidianos escolares: fragmentos de narrativas imagens tecidas em redes pelos sujeitos praticantes. In: . (Org.). Currículo e educação básica: por entre redes de conhecimentos, imagens, narrativas, experiências e devires. Rio de Janeiro: Rovelle, 2011b. p. 17-50.

Pesquisa com o cotidiano. Educação e sociedade: revista de ciências da educação, Campinas, v. 28, n. 98, p. 73-95, jan./abr. 2007b. Disponível em: $<$ http://www.cedes.unicamp.br>. Acesso em: 21 mar. 2012.

OLIVEIRA, Inês Barbosa de Oliveira. Currículos praticados: entre a regularização e a emancipação. 2. ed. Rio de Janeiro: DP\&A, 2005.

SANTOS, Boaventura de Sousa. Renovar a teoria crítica e reinventar a emancipação social. São Paulo: Boitempo, 2007.

VITÓRIA. Secretaria Municipal de Educação. Sistema Municipal de Ensino de Vitória: diretrizes curriculares para o ensino fundamental. Vitória: PMV, 2004. 